Check for updates

London

Cite this as: BMJ 2020;371:m4151 http://dx.doi.org/10.1136/bmj.m4151 Published: 27 October 2020

\title{
EXCLUSIVE
}

\section{Covid-19: Patients to use pulse oximetry at home to spot deterioration}

\section{Ingrid Torjesen}

Patients with covid-19 who don't need immediate hospital attention but are at high risk of developing serious symptoms are to be given pulse oximeters to use at home to reduce the risk of serious deterioration, The BMJ has learnt.

NHS England is believed to have purchased around 200 ooo pulse oximeters for the scheme, which clinical commissioning groups across England will be able to access.

The initiative is set to be rolled out across the country over the next six weeks and is being led by Matthew Inada-Kim, national clinical lead for deterioration at NHS England and a consultant in acute and general medicine at Hampshire Hospitals NHS Foundation Trust.

NHS England has advised since the start of the pandemic that medical intervention is necessary if oxygen saturation levels began to fall. ${ }^{1}$ But during the first wave it became clear that some patients developed "silent hypoxia," where desaturation occurred but they exhibited no obvious symptoms, such as shortness of breath or feeling very unwell. These patients tended to require invasive respiratory support and had poor outcomes.

Nigel Watson, chief executive of Wessex Local Medical Committees, which is expected to be one of the first areas to implement the monitoring at home scheme, told The BMJ that the evidence was now fairly strong that if oxygen saturation fell to $94 \%$ or $93 \%$ the mortality risk increased to around $13 \%$, and if it fell below that level the risk would increase to about $28 \%$.

The idea is to create "virtual covid wards" of patients at risk, such as people aged over 65 years or those under 65 with a chronic condition, and to monitor oxygen saturation through patients taking readings and relating these to their health teams, Watson said. "If it starts dropping and particularly goes to $94 \%$, then you'll potentially take some action, which may include [the patient] being admitted to hospital."

Pilot areas have used various arrangements to monitor patients. In North Hampshire a group of general practices employed two nurse practitioners to run the service, while in Southampton the local GP federation led the service. On the Isle of Wight the service was run by the local hospital.

"You have different delivery models, but essentially the pathway is the same," Watson said.

Rob Barnett, chair of Liverpool Local Medical Committee, confirmed that in his area health officials were working on how "virtual covid wards" could be implemented to ensure admission of patients to hospital "before their levels have dropped too much to make the recovery almost impossible.” But he pointed out that this would put more pressure on the hospital system.

"As we monitor more patients in the community, we will know what the tipping point is for them to get into hospital, which is likely to be earlier than we might do if we weren't monitoring them at all," he said. "So, the recovery will be better, but actually I think it inadvertently means we're going to have even more patients in the hospital."

NHS England and Inada-Kim were asked for comment but had not responded by the time of publication.

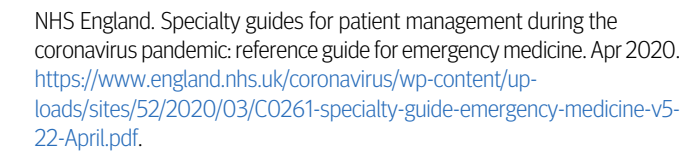

This article is made freely available for use in accordance with BMJ's website terms and conditions for the duration of the covid-19 pandemic or until otherwise determined by BMJ. You may use, download and print the article for any lawful, non-commercial purpose (including text and data mining) provided that all copyright notices and trade marks are retained. 